\title{
LA PARODIA A LA OBRA “EN BUSCA DEL TIEMPO PERDIDO” DE PROUST Y AL "MATADERO" DE ESTEBAN ECHEVERRIA EN EL TEXTO DE ALEJO CARPENTIER
}

\author{
Ma. Salvadora Ortiz
}

\begin{abstract}
Parody is among the most salient constitutive elements in Carpenterian writing. This article attempts to demonstrate the significance of this resource, used by Capentier to establish relationships beyond time and space, between two similar, analogous realities, one of which is explained in terms of its affinity to the other, which may well have occurred centuries before.
\end{abstract}

En El recurso del método son tres las parodias más significativas:

a) $\mathrm{Al}$ discurso racionalista cartesiano;

b) A la obra de Marcel Proust En busca del tiempo perdido; $\mathrm{y}$

c) Al texto que se produjo en la Dictadura de Rosas: "El matadero" de Esteban Echeverría.

Se presentan varios elementos relacionados entre El recurso del método y el mundo que describe Marcel Proust en su obra En busca del tiempo perdido, cronológicamente se ubica de 1874 a 1922 , aproximadamente.

En El recurso del método se presenta ese mundo proustiano, como si los acontecimientos y personajes de En busca del tiempo perdido no hubiesen existido en 1874 sino de 1913 a 1927 , que es el tiempo de El recurso del método. El Primer Tomo de la obra de Proust es publicado en 1913: Du cóté de Chez Swann y el último Le temps retrouvé, en 1927. El recurso del método se inicia en 1913 y concluye en 1927; el epílogo se ubica en 1972.

Esta sobreposición de textos implica una relación cronológica que permite delimitar en qué época vive el Primer Magistrado, y con quiénes quería alternar.

El discurso proustiano se intercala a través de todo El recurso del método, a veces para ser parodiado, o solo como cita o referencia, recuérdese que estas dos formas son elementos constructivos del discurso Barroco.
El nombre de Proust no se cita ni una sola vez en toda la novela, sin embargo, es importante anotar dos aspectos comunes en la estructura de ambos textos que funcionan como parodias constructivas:

a) el primero es que ambas obras están divididas en siete, En busca del tiempo perdido consta de siete partes: Du cóté de chez Swann, A l'ombre des jeunes filles en fleurs, Du Cóté de Guermantes, Sodome et Gomorrhe, La prisonniére, Albertine disparue et le temps retrouvé. El recurso del método también consta de siete capítulos.

b) El otro aspecto que funciona como parodia constructiva es que en ambas obras se presenta como recurso, un fenómeno que a veces ocurre cuando nos despertamos, y nos encontramos en estado de semi-conciencia, sin saber con exactitud en dónde se está. A veces se siente la persona en otro lugar, en otra casa, o en otro país, y por consecuencia en otro tiempo diferente del real.

Este recurso que se presenta en la novela constituye una parodia constructiva con respecto al texto proustiano: sirve para ubicar El recurso del método en un espacio y tiempo concreto.

Los dos textos se inician con este despertar sin saber con exactitud en donde se está, véanse ambos textos: 


\begin{abstract}
“...quand je me réveillais ainsi, mon esprit s'agitant pour chercher, sans y réussir, á savoir où j'étais, tout tournait autour de moi dans l'obscurité, les choses, les pays. Mon corps, trop engourdi pour remuer, cherchait, d'aprés la forme de sa fatigue, à repérer la position de ses membres pour en induire la direction du mur, la place des meubles, pour reconstruire et pour nommer la derneure oir il se trouvait. Sa mémoire de ses cotes, de ses genoux, de ses épaules lui présentait successivement plusieurs des chambres oú il avait dormi, tandis qu' autour de lui les murs invisibles, changeant de place selon la forme de la piéce imaginée, tourbillonnaient dans les ténebres. Et avant même que ma pensée, qui hésitait au seuil des temps et des formes eut identifié le logis en rapprochant les circonstanies, lui-mon corps, - se rappelait pour chacun le genre du lit, la place des portes, la prise de jour des fênetres, l'existence d'un couloir, avec la pensée que j'avais on m'y endormant et que je retrouvais au réveil" (1)
\end{abstract}

\section{Ahora véase el texto de Carpentier:}

“...pero si acabo de acostarme. Y ya suena el timbre. Seis y cuarto. No puede ser. Siete y cuarto, acaso. Más cerca. Ocho y cuarto. Este despertador será un portento de la relojería suiza, pero sus agujas son tan finas que apenas si se ven. Nueve y cuarto. Tampoco. Los espejuelos. Diez y cuarto. Eso sí. Además el día se pinta en color de media mañana sobre el amarillo de las cortinas. Y es lo mismo de siempre cuando vuelvo a esta casa: abro los ojos con la sensación de estar allá, por la hamaca esta que me acompaña a todas partes - casa, hotel, castillo inglés, Palacio nuestro..

Y es otra mecida y un bostezo, y otra mecida al sacar las piernas y poner los pies a buscar más pantuflas que se me extravían en los colores de la alfombra persa. (Allá, siempre atenta a mis despertares, me las hubiera alcanzado ya la Mayoraba Elmira, que debe estar durmiendo en su camastro de campaña, ella también sus manías-, de pechos sueltos y enaguas por las caderas en la noche del otro hemisferio. (P. 11)

En ambos textos se da la misma connotación de imprecisión al despertar en el texto de Proust al no saber donde se encuentra el personaje, se remite al pasado, y como él mismo dice: "repasó las diferentes habitaciones en donde había estado". En el caso de Carpentier el personaje se siente perdido en el tiempo lo que lleva al Dictador, a un estado de añoranza por su país, su medio, su habitación, su despertar "allá", América Latina. Este va a ser el lugar con el cual el Dictador se va a identificar, con quien logrará, su identidad al término de su vida.

Por medio de este recurso en el Capítulo primero, que es como una especie de "overtura", se presentan los diferentes lugares en que se ubicará la acción en ambos textos. Como es el caso de $E l$ recurso del método, que oscila entre un constante "allá" y "aquî", que corresponde a veces a Francia y a veces a América Latina de acuerdo con la ubicación en que se encuentre el Dictador.
Este despertar sin saber con exactitud en dónde se está se presenta además de los ejemplos citados anteriormente en el Capítulo III (P. 133), en Capítulo IV (P. 176), en el Capítulo VI (P. 267-268) y en el Capítulo VII (P. 337). Y En busca del tiempo perdido en Du cóté de Guermantes (Chapitre II), Sôdome et Gomorrhe (Chapitre III), La prisonnière (Chapitre I), y en Albertine disparue (Chapitre I et II) y en Le temps retrouvé.

Otro aspecto que se parodia en El recurso del método son algunos de los personajes, de Proust. Es evidente que los personajes de ambas novelas son construídos con base en personajes reales; en el caso de Carpentier toma personajes literarios de la novela de Proust o que tuvieron relación con dicho escritor en su vida y los incorpora a su novela: como Reynaldo Hahnn, Louise de Mornand, Dr. Fournier, Elstir, Vinteuil, Madame de Verdurin, Charles Morel, Brichot, Forcheville y Calmette.

Los personajes proustianos con los que intenta integrarse el Dictador pertenecen a la rica burguesía, decimos intenta ya que por ejemplo él asiste a tres reuniones en casa de Madame Verdurín (personaje ficticio) pero no logra establecer ninguna relación de amistad continua, significativa dentro de este grupo. Lo que prueba que El Dictador no logra ni estar en los círculos de ficción; es un personaje marginal perteneciente a una cultura marginal.

Madame Verdurin se casa con un aristócrata y pasa a ser noble, una princesa. Véase en el siguiente texto la alusión que el Dictador hace a dichas reuniones:

"Se había abierto a un camino que, sin amarlo hasta las cumbres del Gotha, lo había conducido sin embargo, por tres veces, a las veladas musicales de Madame Verdurin - lo cual no era un mal comienzo". (P. 96)

Incluso el mismo Presidentee se puso sus propios límites, aunque Madame Verdurin era de dudosa reputación (P. 317) no se atrevió a llamarla cuando fue derrocado.

"En tales días no me atrevía a llamar por teléfono a Madame Verdurin - ahora princesa por matrimonio. Temía que una princesa - o con humos de tal - hiciese un desdén a quien no era en suma, sino un presidente latinoamericano arrojado de su palacio". (P. 307)

Del mundo artístico proustiano son varios los personajes que se insertan en la novela unos como Elstir, y Charles Morel que son del mundo de En busca del tiempo perdido y otros como Reynaldo 
Hahn que fue amigo personal de Marcel Proust, y Vinteuil compositor de esa época.

Hahn el 9 de agosto de 1875 nace en Venezuela y muere en París el 28 de enero de 1947. Director de orquesta y crítico musical en el periódico "Fígaro". Llega a Francia a la edad de tres años, admitido en el conservatorio de París a los once años. Dirigió la orquesta sinfónica de Cannes. En 1945 fue Director de la Opera de París.

Hahn fue confidente de Proust y de Hahn, Proust adquiere su cultura musical. En El recurso del método es él quien le dice al Director que en París están enterados de la masacre de la Nueva Córdoba.

\begin{abstract}
"Acaso sería oportuno llamar a Reynaldo Hahn su amable y ameno "paisano" de Puerto Cabello. El compositor acudió al teléfono, hablándole en su grato español de acento venezolano no singularizado" - era hábito que él mismo no estaba a explicarse - por unos giros de marcada inflexión río platense. Después de los saludos usuales, Reynaldo, en el tono blando, lento y peresozo, que era el suyo, como quien, habla de otra cosa, le informó que Le Matin había publicado, sobre los acontecimiento de "Ajyá", una serie de reportajes feroces, donde su "paisano" era calificado de "carnicero de Nueva Córdoba". (P. 94)
\end{abstract}

Hahn también se cita en las páginas 107 y 305 en la obra de Carpentier Ese músico que llevo dentro en Tomo II, P. 396, Tomo III, P. 92.

De Charles Morel, violinista se dice en El recurso del método:

"Llamó el violinista Morel, que lo felicitó por su regreso con el tono presuroso y evasivo de quien desea dar rápido término a una conversación". (P. 93)

Los otros dos artistas que se toman de Proust en El recurso del método son Vinteuil, músico, y a Elstir pintor. En el texto de Proust se citaron por primera vez cuando en casa Madame Verdurin hay una reunión musical y se escucha la "frase musical" de Vinteuil, ahí conoce el Protagonista de En busca del tiempo perdido a Albertine; también ahí se conoce la pintura de Elstir.

Vinteuil se cita varias veces en $E l$ recurso del método, la referencia más importante es cuando el Dictador regresa a París, una vez derrocado, en período de entre guerras, momento en que surgen los movimientos de vanguardia:

"En música ocurría algo parecido: nadie tocaba ya las obras de Vinteuil menos su Sonata - fuera de las jovencitas, alumnas de conservatorios, que vueltas de sus clases de piano, las dejaban dormir en alguna gaveta para entregarse a rarezas". (P. 307)

Elstir ocupa varias páginas de En busca del tiempo perdido, Proust nos dice de él:
"Le tableau d'Elstir ne sont pas qui a demi-resemblants, a demiresemblants, a demi-seulment même lorsque ses modeles sont, non pas des personnes, mes de fleurs (Elstir ne pouvent regarder fune fleur qu'en la transplantant d'abord dodns le jardin intérieur où nous sommes forcés de rester toujours. Il avant montré dans cette aquarelle l'apparition de roses qui il avait vues, et sans lui on n'eût connues jamais" (2).

Este pintor (3) lo toma Carpentier y no sólo lo cita sino, que en El recurso del método lo hace evolucionar, lo desarrolla. Elstir después de la guerra busca ponerse al día con los movimientos de vanguardia, cosa que no sucede en la obra de Proust:

"Me enteré - en eso Ofelia había dicho la verdad- que la pintura de Elstir había descendido mucho en la estima del público: sus deliciosas marinas convivían ya, revueltos, en galerías de menor cuantía, con cualquier arte que para los nuevos ricos nacidos de la guerra, tratara de olas, y olas, arnas y espumas. Amargado por el descenso de sus valores, se había retirado rabiosamente en su estudio de Balbec, tratando de alcanzar una "modernidad" que, por deformar su estilo personal sin añadirle nada, se traducía en desconcertantes búsquedas tan poco gustadas por sus admiradores de ayer como por quienes, ahora, seguían las nuevas corrientes". (P. 306)

Otros dos personajes que se citan en El recurso del método, pero no aparecen En busca del tiempo perdido son Louise de Mornand (P. 95) que sostuvo una relación epistolar con Proust y el Doctor Fournier (4) que es uno de los médicos del Dictador y fue médico del padre de Proust (1870). Vemos como en este caso se inserta en el relato un personaje que pertenece a otro tiempo del que se ubica el Dictador.

Brichot, Forcheville y Camette editor del Fígaro son también citados en El recurso del método. Estos personajes son elementos constitutivos de esta parodia constructiva en dicho texto.

El contexto culinario en Proust cumple una función muy importante, por medio de los diferentes elementos (signos) constitutivos de este contexto, el narrador nos remite al pasado, busca el tiempo -ido-.

Esta búsqueda no es simplemente del tiempo pasado, un esfuerzo para recordar, una exploración de la memoria, esta es también una búsqueda de la verdad. Esto es motivado en parte en Proust, por su platonismo: aprender al fin y al cabo es recordar. Pero por importante que sea su papel, la memoria no interviene sino como aprendizaje. El aprender atañe esencialmente a los signos (5). Todo lo que nos enseña algo emite signos y todo acto de aprendizaje es una reelectura o interpretación de signos. 
Recuérdese por ejemplo el pasaje de las "magdalenas" y las "hojitas de té" en la obra En busca del tiempo perdido que las utiliza el narrador para remitirse al pasado y muestra éste su infancia.

La utilización del contexto culinario para remitirnos al pasado es parodiado en El recurso del método. El ejemplo más revelador es lo que le sucede a Ofelia, hija del Primer Magistrado; la Mayoraba Elmira, la empleada, prepara una cena latinoamericana con gran variedad de platos y bebidas como dijo ella "a la usanza de allá" (Esto sucede cuando el Primer Magistrado es destituido del poder y se van a radicar a París).

Elmirita, como cariñosamente se le llamaba, compra los ingredientes, prepara la comida y la sirve, todo al estilo latinoamericano. Esta cena hace que a Ofelia los olores (signos de la comida), le evoquen su infanccia, sus raíces, parte de su identidad.

\section{El texto siguiente lo narra:}

"Entiendo mejor lo que ocurría, Ofelia devolvió su delantal a la cocinera, y, envolviéndose en una bata subió al desván... El Primer Magistrado y el Cholo Mendoza, despechugados, hirsutos, sin rasurar - y muy bien bebidos, por lo visto- estaban sentados junto a una larga mesa que no era, en realidad, sino una puerta levantada de sus charmelas y puesta sobre dos sillas. Varias bandejas y platos presentaban ahí, como dispuestos en suntuoso bodegón tropical, los verdores del guacamole, los rojos del ají, los ocres achocolatados de salsas donde emergían pechugas y encuentros de pavo, escarchados de cebolla rallada. Alineadas sobre una tabla de trinchar había chalupitas y enchiladas, junto al amarillo de los tamales envueltos en hojas calientes y húmedas, que despedían vapores de recogijo aldeano". (P. 314).

Y así se continúa enumerando más platos latinoamericanos hasta que interviene el Cholo Mendoza invitándola a sentarse, y ella le contesta:

\footnotetext{
“¿Y quién armó todo esto? - preguntó Ofelia, aún atolondrada por el brusco despertar y los gritos de la cocinera. - "Elmiritarespondió la parda, haciendo reverencias de pantorrillas cruzadas, como las hacían las jóvenes educadas, en colegios de dominicas francesas. Ofelia estuvo por patear la improvisada mesa y acabar violentamente con el holgorio. Pero ahora un tamal de maíz alzado en tenedor, acercaba a sus ojos, descendiendo hacia su boca. Cuando la tuvo frente a la nariz, una emoción repentina, venida de adentro, de muy lejos, de un pálpito de entrañas, le ablandó las corvas, sentándola en una silla. Mordió aquello y, de súbito, su cuerpo se le aligeró de treinta años. Estaba de calcetines blancos, recojidos los moños con papelillos de China, en el patio de los metates y del tamarindo. Y bajaban hacia ella las pardas pulpas del árbol, metidas en sus crujientes estuches de pergamino canela, trayéndole un agraz agridulce que le ponía, bajo la lengua, olvidadas salivas. Y aquel devuelto olor de guayabas fermentadas..." (P. 315)
}

$\mathrm{Y}$ así consecutivamente se sigue recordando los diferentes "sabores" de su infancia en América Latina, y con ello el recuerdo de los sonidos en su csa de campo como la vaca Flor de Mayo, que recién parido llamaba a su ternero para que le aligerara las ubres, y el pregonero de las melcochas. Así continúa hasta traer el recuerdo de una imagen de su infancia:

"Tengo siete años, y cada mañana, me miro ya en el espejo para ver si durante la noche, me han salido tetas - entrándome por los poros. Tengo siete años:

Santa María

Líbranos de todo mal;

ampáranos señora,

d'este tremendo animal" (P. 315)

Y así continúan las reminicencias de su pasaddo, el cual lo añora Ofelia, a nivel pulsional.

Veamos el papel tan importante que en este caso tiene la utilización de la parodia como elemento característico del discurso Barroco. De hecho por medio de este se logra describir una serie de rasgos propios de la cultura latinoamericana, que son las comidas y la forma en que estas se sirven. Así como canciones de la época.

Esta secuencia de la cena latinoamericana en París (P. 314-316), es lo suficientemente elocuente con respecto a la parodia de los alimentos como medio de evocación del pasado, que utiliza Proust.

En El recurso del método hay dos frases paródicas. Una que hace alusión al segundo tomo de En busca del tiempo perido: A la sombra de las muchachas en flor en que el narrador nos describe la tranquilidad en que se estaba cuando ya se había vencido a Hoffmann y el inicio de la guerra.

"Sosiego y reposo hallaba, por fin, el Primer Magistrado, a la sombra de los cañones en flores”. (P. 146)

Y la otra parodia evidente es al título del cuarto tomo de su obra, Sodoma y Gomorra, tomo en el que Proust critica las costumbres, entre otras, las homosexuales de ia sociediad de esa época y dice así el texto parodiador:

"Y esta orgullosa y pervertida metrópoli conocería una purificación por el fuego que más de un escritor católico de aquí hubiese presentido, comparándola con Sodoma y Gomorra..."(P. 115).

Un asunto de interés que se plantea en El recurso del método, con respecto a Proust es la oposición al gusto musical entre éste y el Dictador, que se conoce por medio de la ópera de Debussy Peleas 
y Melisenda la cual gustaba mucho a Proust y el Dictador no logra ni entenderla, ni ubicarla dentro del contexto cultural universal, lo cual prueba la incultura de éste (6).

La parodia a Proust tiene relación significativa con la parodia a Descartes, el Primer Magistrado muere en 1924, período de entre guerras, en que el arte sufre un corte por la teoría sicoanalítica de Sigmund Freud; el discurso cartesiano pierde vigencia, Proust fundamenta su discurso en la desintegración de esos principios que para Descartes es la forma en que la realidad funciona, Proust logra ésto al establecer otras relaciones entre la conciencia, el tiempo y el espacio.

El Dictador pretende ser cartesiano e insertarse dentro de esa burguesía legitimada por dicho discurso en determinado momento; pero en Francia perdía vigencia, validez al darse énfasis a lo pulsional, a lo intuitivo, a lo emocional. Esto pone en evidencia el "retraso" epistemológico del Presidente.

\section{La parodia de "El Matadero" de Esteban Eche- verría.}

La Dictadura de Rosas, en Argentina fue una de las más sangrientas en América. Rosas polariza las pasiones políticas de su época. Este estuvo en el poder de 1829 a 1832 y de 1835 a 1852 .

"En Argentina la identificación del intelectual con las ideas europeas más avanzadas tuvo una importancia decisiva bajo la dictadura de Rosas, cuya defensa de los intereses rurales lo hizo despreciar las modas importadas de Europa tanto en las costumbres como en las ideas políticas" (7).

Como consecuencia de esta dictadura, se genera un discurso diseminado en diarios, panfletos y periódicos, de corte contestatario en su mayoría; y otro hecho por los enemigos de la prescripción (Alberdi, López, Gutiérrez, Mitre, Sarmiento y Echeverría), los que producen una serie de textos literarios de primera calidad, que creó toda una imagen mítica de ese sistema.

Tres obras en prosa se destacan en ese período, Facundo (1845), Amalia (1851) y El matadero. Este último se parodia en El recurso del método. Y Facundo de Sarmiento se cita:

"Al día siguiente, luego de adquirir en Brentano's una preciosísima edición del Facundo de Sarmiento- lo cual le hizo emitir amargos conceptos sobre el dramático destino de los pueblos latinoamericanos, siempre trabajados en combate maniqueísta entre civilización y barbarie entre el progreso y el caudillismo". (P. 42)
Esteban Echeverría, autor del cuento "El Matadero", es el iniciador del romanticismo argentino. Nace en Buenos Aires el 2 de setiembre de 1851 y muere en Montevideo en 1851.

Este es uno de los primeros cuentos latinoamericanos, Seymon Menton nos dice al respecto:

"Aunque la representación de una dictadura el cuento sanguinolenta por un matadero parece bastante obvia, se eleva por encima de otras obras antirrosistas por la articulación ingeniosa de un relato dinámico, con una introducción intelectual" (8).

Lo que se plantea en forma global en "El matadero" es una comparación entre el hecho real de la crueldad de un matadero y la dictadura de Rosas. En El recurso del método lo que se parodia es esta "connotación de masacre de crueldad" que se da en los regímenes totalitarios. La parodia se da concretamente en la secuencia de El recurso del método que relata el genocidio de Nueva Córdoba. Esta masacre se describe en la Quinta y Sexta parte de los Capítulos II y III respectivamente.

Veamos como algunos ciudadanos fueron llevados al Matadero Municipal al igual que las reses en el cuento:

"Y los últimos combatientes - unos treinta o cuarenta fueron llevados al Matadero Municipal donde entre cueros de reses, vísceras, tripas y pieles de animales, sobre charcos de sangre coagulada se les colgó de los garfios y garabatos, por las axilas, por las corvas, por los costillares o el mentón, después de magullarlos a patadas y a culatazos - ¿Quién quiere carne al pincho? ¿Quién quiere carne al pincho? - gritaban los ejecutores en remedo de pregoneros, dando otro bayonetazao a un agonizante, ...". (P. 82)

El subrayado del texto anterior es nuestro y se hace para resaltar uno de los elementos más relevantes de la parodia como es la gran cantidad de sangre que se describe en este ambiente al igual que en El matadero, (9) veamos algunos pasajes de este último en que la sangre es una constante:

\footnotetext{
"Hacia otra parte, entre tanto, dos africanos llevaban arrastrando las entrañas de un animal; allá una mulata se alejaba con un ovillo de tripas y resbalando de repente sobre un charco de sangre, caía a plomo, cubriendo con su cuerpo la codiciada presa". (P. 22)
}

"De repente caía un bofe sangriento sobre la cabeza de alguno" (P. 23).

Otro hecho cruel que se describe es la muerte del niño:

“...Una cabeza de niño cuyo tronco permaneció inmóvil sobre su caballo de palo, lanzando por cada arteria un largo chorro de sangre". (P. 25) 
Y así sucesivamente se repiten estas imágenes sanguinolentas.

Otro elemento que se parodia es el ambiente. Véase como es descrito en El recurso del método:

"Ya los zamurros, buitres y auras volaban bajo sobre los patios del Matadero Municipal”. (P. 82)

Otro hecho que se parodia es la forma en que arrastran a las personas como animales. Véase como es arrastrado el joven unitario en "El Matadero":

“¡Mueran! ¡Vivan! repitieron en coro los espectadores y atándole codo a codo, entre moquetes y tirones, entre vociferaciones e injurias, arrastraron al infeliz joven al banco del tormento como los sayones de Cristo". (P. 31)

Y como eran arrastrados en El recurso del método algunos sublevados:

"Algunos fugitivos, enlazados como novillos en rodeo, eran arrastrados por la caballería sobre los suelos de adoquines y chinas pelonas". (P. 82)

Al Dictador se le llama carnicero (P. 94); es importante destacar que no solo en el Matadero Municipal se da el genocidio, sino también en la Iglesia (P. 82). Recuérdese que la Iglesia juega un papel importante en la Dictadura de Rosas.

En los textos arriba comentados se vio cómo se parodia "El matadero" en El recurso del método, siguiéndose en ambos textos la misma línea de discurso al mostrar la injusticia de la dictadura. En el caso de El recurso del método el que representa la arbitrariedad es el Dictador y en "El matadero" el Juez y los ejecutantes de dicha arbitrariedad, los militares y los carniceros representados por Matasiete.

Un personaje parodiado es Miguel Estatua el cual se suicida en una explosión de cartuchos de dinamita, hecha por él, ante la indignación de la derrota (P. 82), al igual que el joven unitario que explota pero de cólera en "El matadero".

"Sus fuerzas se habían agotado - inmediatamente quedó atado en cruz y empezaron la obra de desnudarlo. Entonces un torrente de sangre brotó borbollonenado de la boca y las narices del joven y extendiéndose empezó a caer a chorros por entre ambos lados de la mesa. Los mayores quedaron inmóviles y los espectadores estupefactos.

- Reventó de rabia el salvaje unitario - dijo uno.

- Tenía un río de sangre en las venas - articuló el otro". (P. 34)

Ambos personajes son símbolo de la no aceptación del régimen.

\section{CITAS}

(1) Marcel, Proust. Du côté de chez Swann. Folio, París, 1982 (pp. 14-15).

(2) León Guichard. Introduction à la lecture de Proust. Nizet, Paris, 1969. (p. 40).

(3) En la pág. 16 de El recurso del método se describe una de sus pinturas.

(4) En las páginas 108,334 y 336 de El recurso del método se hace referencia a dicho personaje.

(5) Cfr. Guilles Deleuze "Proust y los signos". En Ideas y valores Revista del Departamento de Filosofía y Humanidades de la Facultad de Ciencias Humanas de la Universidad Nacional, No. 88-89, 1979. pp. 3 y 4.

(6) Cfr. concepto de cultura de Carpentier en Un camino de medio siglo y otros ensayos. p. 17.

(7) Jean Franco. La cultura moderna en América Latina. Joaquín Mortiz, México, 1971. p. 14.

(8) Seymoun Menton. El cuento Hispanoamericano. Fondo de cultura Económica, México, $3^{\circ}$ Edición, tomo I y II, 1964. p. 35 .

(9) "El matadero" de Esteban Echeverría. En Seymoun Menton. El Cuento Hispanoamericano. pp. 13-37.

\section{BIBLIOGRAFIA}

\section{OBRAS DE ALEJO CARPENTIER.}

\section{Ensayos y artículos:}

Carpentier A. "Conciencia e identidad de América Latina", Razón de ser. Cuba: Editorial de letras cubanas, 1980, pp. 1-10.

. Ese músico que llevo adentro. La Havane: Editorial letras cubanas 3, 1980.

\section{Obras Narrativas:}

Carpentier, A. El recurso del método. 2e. éd. (1ére édition 1974). México: Siglo XXI Editores. 1974.

\section{Otras obras:}

Carpentier, A. "Confesiones sencillas de un escritor barroco". Cfr. Bibliographie "Leonte César".

. "Manita en el suelo", Obras completas. México: Siglo XXI. 1983. pp. 240-261. 


\section{Sobre la obra de Alejo Carpentier:}

Acevedo, F. "Estructura temporal e historia en la ubra de Carpentier", Sin nombre. Puerto Rico: pp. 39-59.

Bueno, S. "Notas para un estudio sobre la concepción de la historia en Alejo Carpentier". Universidad de La Habana (195 ), La Havane: 1972. pp. 122-138.

Palermo, Z. et Al. Historia y mito en la obra de Alejo Carpentier. Buenos Aires: Fernando García Cambeiro, Editor. 1972.

Valdes, Bernal, S. "La caracterización lingüística en Alejo Carpentier", La Universidad de La Habana (124). Departamento de actividades culturales. La Havanne: mai - aoút 1981. pp. 134149.

\section{Sobre "El recurso del método":}

Couffon, C. "Le nouveau portrait d'un dictateur", Le monde. 28 juin 1975. p. 25.
Dellepiane, A. "Tres novelas de la dictadura: 'El recurso del método', 'El otoño del patriarca', 'Yo el supremo'", Caravelle (29). Université de Toulouse: 1977. pp. 65-87.

Dorffmann, A. "Entre Proust y la momia americana", Revista Iberoamericana 67 (114-115). Pennsylvannia: janv. juin 1981. pp. 95-128.

Eguzquiza, j. "El recurso del método", Revista de crítica literaria latinoamericana 1 (2). Lima: 1975. pp. 142-144.

Gribanov, A. "El nombre como factor constructivo en las novelas de Alejo Carpentier", América Latina 2. Russie: 1980. pp. 205-228.

Usabiaga, M. "Alejo Carpentier y su Primer Magistrado", Texto crítico (3) Xalapa, Veracruz: janv. - avril 1976. pp. 128-140.

Vich, Campos M. “' 'El recurso del método' de Alejo Carpentier", (Paul Verdevoye Coord.) "Caudillos", "Caciques" et Dictateurs dans le roman hispano-américani. Paris: Editions hispaniques. 1978. pp. 78-87. 
